\title{
A comparison between seven Swiss and seven German hospitals concerning the use of coercive measures Renate Bernhardsgrütter
}

\author{
Address: Psychiatrische Klinik, Zürcherstr. 30, 9500 Wil, Switzerland \\ from WPA Thematic Conference. Coercive Treatment in Psychiatry: A Comprehensive Review \\ Dresden, Germany. 6-8 June 2007 \\ Published: 19 December 2007 \\ BMC Psychiatry 2007, 7(Suppl I):SI35 doi:I0.1I86/I47I-244X-7-SI-SI35
}

This abstract is available from: http://www.biomedcentral.com/I47I-244X/7/SI/SI35

(c) 2007 Bernhardsgrütter; licensee BioMed Central Ltd.

\section{Background}

In 2004, two independent working groups in Germany and Switzerland compared the frequency and duration of coercive measures in standard psychiatric care across 14 psychiatric hospitals in Germany and Switzerland. The objective was to establish an international knowledge transfer process in order to reduce the frequency and duration of coercive measures on a long-term basis to an extent of necessity.

\section{Methods}

The incidence and duration of mechanical restraint and seclusion was reliably recorded across 7 Swiss and 7 German psychiatric hospitals during the one year period of 2004. Hospital structure characteristics and guidelines on coercive measures were analyzed.

\section{Results}

The results showed different patterns in the use of seclusion and restraint across Swiss and German hospitals. In the Swiss hospitals seclusion was more frequently used than restraint, whereas in German hospitals restraint was more frequently used than seclusion. The average duration of coercive measures was of significantly longer duration in Swiss than in German hospitals. The number of coercive measures per affected case was significantly higher in German than in Swiss hospitals. Associations of data on coercive measures with hospital structure characteristics and guidelines were significant.

\section{Conclusion}

International comparisons on coercive measures allow for knowledge transfer and critical reflection of national traditions in the use of coercive measures. The results clearly showed different patterns in the use of seclusion and mechanical restraint across Swiss and German hospitals.
Hospital structure characteristics as well as the use of guidelines on coercive measures were associated with the frequency and duration of coercive measures, in German as well as in Swiss hospitals. 